Journal of Business Management Education | Volume 3, Number 1, May 2018, page. 97-106

\title{
GAMBARAN KUALITAS INFORMASI ,SHOPPING ENJOYMENT DAN KEPUTUSAN PEMBELIAN PADA FOLLOWERS INSTAGRAM KAMAR GADGET
}

\author{
R. Nur Muhammad \\ Universitas Pendidikan Indonesia \\ R.Nur Muhammad @upi.edu \\ L.A. Wibowo \\ Universitas Pendidikan Indonesia \\ LiliAdiWibowo@upi.edu \\ Lisnawati \\ Universitas Pendidikan Indonesia \\ lisnawati@upi.edu
}

Tujuan - Tujuan penelitian ini adalah untuk melihat gambaran kualitas informasi ,shopping enjoyment dan keputusan pembelian

Desain/metodologi/pendekatan - Desain penelitian ini adalah cross sectional method. Penelitian ini menggunakan pendekatan deskriptif dengan metode explanatory survei. Sebanyak 240 responden dipilih dengan menggunakan probability sampling. Sebuah angket digunakan sebagai instrumen penelitian untuk mengumpulkan data dari responden. Teknik analisis yang digunakan adalah teknik deskriptif dengan menggunakan distribusi frekuensi.

Temuan - Berdasarkan hasil penelitian menggunakan analisis deskriptif, didapatkan hasil kualitas informasi berada dalam kategori sangat tinggi dengan skor $83,95 \%$, shopping enjoyment dan keputusan pembelian berada dalam kategori tinggi dengan skor masing-masing 83,88\% dan 83,30\%.

Orisinalitas/nilai - Penelitian ini memberikan dasar untuk memahami isu-isu lingkungan kerja, kepuasan kerja dan loyalitas karyawan. Perbedaan penelitian ini dengan penelitian sebelumnya adalah terletak pada objek yang merupakan perusahaan onlineshop yaitu Instagram Kamar Gadget, dengan variabel yang diteliti yaitu kualitas informasi ,shopping enjoyment, serta menggunakan teori atau referensi yang berbeda dengan peneliti sebelumnya.

Kata Kunci: kualitas informasi ,shopping enjoyment dan keputusan pembelian

Jenis Artikel: Studi Kasus

\begin{abstract}
Purpose - The purpose of this study is to see the picture quality of information, shopping enjoyment and purchasing decisions

Design/methodology/approachh - The design of this study is cross sectional method. This research uses descriptive approach with explanatory survey method. A total of 240 respondents were selected using probability sampling. A questionnaire was used as a research instrument to collect data from respondents. The analysis technique used is descriptive technique by using frequency distribution.

Findings - Based on the results of the study using descriptive analysis, the results obtained the quality of information is in very high category with a score of $83.95 \%$, shopping enjoyment and purchase decisions are in high category with a score of $83.88 \%$ and $83.30 \%$ respectively.

Originality/value - This research provides a basis for understanding work environment issues, job satisfaction and employee loyalty. The difference of this research with the previous research is located on the object which is the company of onlineshop Instagram Gadget Room, with the variables studied are the quality of information, shopping enjoyment, and using theory or reference different from previous researchers..
\end{abstract}

Keywords: quality of information, shopping enjoyment and purchasing decisions

Article Type : Case Study 


\section{PENDAHULUAN}

Manajemen pemasaran merupakan bagian penting dalam perusahaan untuk mengetahui dan memahami kebutuhan dan keinginan konsumen sehingga produk dan jasa yang ditawarkan dapat relevan dengan keinginan konsumen (Nasrabadi \& Zandi 2015). Revolusi pada bidang ekonomi ditandai dengan berkembangnya bisnis berbasis internet atau jual beli online. Teknologi dan Internet telah mengubah cara pemasaran (Raman \& Annamalai 2012).

Dalam beberapa tahun terakhir Nielsen Global Online menunjukkan perilaku konsumen online shopping di Indonesia yang cukup unik. Masyarakat Negara maju cenderung membeli barangbarang elektronik atau produk IT secara online, namun barang tersebut kurang laku di Indonesia. Memasarkan produk secara online merupakan salah satu cara untuk bisa memperluas pasar ke daerahdaerah yang sulit dijangkau dari toko sehingga konter-konter penjual handphone dirasa perlu untuk mulai menawarkan produknya secara online.

Memahami perilaku konsumen ketika belanja dan membuat keputusan pembelian secara online juga penting dalam tujuan meningkatkan bisnis online para pemasar(Akhlaq, A., \& Ahmed 2015). Pengusaha yang tidak mempromosikan produknya melalui internet akan merugi dan tergeser karena melakukan komunikasi pemasaran melalui internet sangatlah efektif (Kusumadewi, A., \& Bobby 2012). Internet dapat memudahkan konsumen untuk menghemat waktu dalam melakukan kegiatan jual beli secara online, keuntungan tersebut juga menciptakan potensi besar untuk mengembangkan kegiatan jual beli online, namun pada kenyataannya semakin banyak konsumen yang menggunakan media internet untuk mendapatkan informasi mengenai produk tetapi tidak melakukan pembelian (Lim, W. M., \& Ting 2012)

Perusahaan riset We Are Social pada 26 Januari 2017 mengumumkan laporan terkait perkembangan pengguna internet di seluruh dunia, hasil risetnya menunjukan bahwa Indonesia merupakan Negara dengan pertumbuhan jumlah pengguna internet terbesar di dunia. Pada awal tahun 2016 Indonesia hanya mempunyai 88,1 juta pengguna Internet, jumlah tersebut telah naik sebesar $51 \%$ menjadi 132,7 juta pengguna pada awal 2017. Sedangkan dari sisi perangkat yang digunakan untuk mengakses internet tidak ada perubahan yang berarti. Sebanyak 69\% masyarakat Indonesia masih mengakses internet melalui perangkat mobile, dan sisanya melalui desktop dan tablet.

Pertumbuhan jumlah pengguna internet diiringi dengan meningkatnya jumlah pengguna layanan media sosial. Tahun lalu jumlah pengguna media sosial berjumlah 79 juta, angka tersebut kini telah naik menjadi 106 juta pengguna. Para pengguna yang secara aktif menggunakan media sosial di perangkat mobile pun naik dari angka 66 juta menjadi 92 juta. Dari segi pertambahan jumlah pengguna di layanan media sosial tersebut, Indonesia bahkan menempati posisi ketiga di dunia. Google Indonesia menggelar survei perilaku belanja secara online dengan melibatkan 1.300 responden yang memiliki akses internet. Para konsumen dalam berbelanja secara online biasanya melakukan riset melalui mesin pencari sebesar $41 \%$ dan jejaring sosial atau media sosial sebesar $37 \%$. Sisanya meliputi situs retailer atau toko sebesar $20 \%$ lalu website berita/majalah, blog/forum/message board, email/newsletter, serta website perbandingan produk dengan persentase masing-masing sebesar $14 \%$.

Berdasarkan Nielsen Global Online, perilaku masyarakat Indonesia lebih sering membeli profuk fashion secara online. sedangkan handphone berada di peringkat ke- 6 sebagai barang yang sering di beli secara online dengan presentase hanya sebesar $5,1 \%$. Fenomena tersebut membuktikan bahwa keputusan untuk berbelanja handphone secara online di Indonesia masih rendah. Rendahnya keputusan pembelian secara online pada industri ini serta bertambahnya jumlah pemasar, menyebabkan persaingan antar perusahaan dalam memperebutkan jumlah konsumen.

Banyaknya pesaing yang menawarkan produk dalam penjualan secara online juga membuat setiap pemasar semakin kompetitif dalam upaya menarik para konsumen untuk memutuskan dalam melakukan pembelian. Tingginya tingat persaingan dan rendahnya minat masyarakat Indonesia untuk berbelanja handphone secara online menjadi tantangan tersendiri bagi Kamar Gadget untuk berusaha menarik konsumen agar membeli produknya dengan berbagai macam strategi..

Kamar Gadget sebagai salah satu starup yang menjual handphone secara online di Bandung 
menyediakan informasi mengenai produk secara akurat, baik itu tentang ukuran, jenis/tipe, serta kondisi produknya. Informasi yang disajikan juga up to date, kamar gadget juga memberi respon diskusi dan bukti pengiriman pada konsumennya, selain itu informasi mengenai kelengkapan panduan proses belanja, pembayaran, hingga pengiriman disediakan secara relevan (Resa et al. 2009)

Selain memberikan informasi yang berkualitas dengan harapan dapat meningkatkan keputusan pembelian konsume, kamar gadget juga memperhatikan kenyamanan konsumen saat berbelanja. Kamar Gadget selalu mengupayakan agar konsumen memahami proses transaksi, memberikan review produk, dan testimoni. Keberagaman dan keunikan produk yang disediakan juga diharapkan mampu membuat konsumen nyaman saat berbelanja sehingga dapat meningkatkan tingkat keputusan konsumen untuk berbelanja handphone di Kamar Gadget (Tarmedi \& Asri n.d.) Meningkatnya budaya belanja online tersebut menghadirkan fenomena baru yang saat ini sedang berkembang yaitu munculnya toko online yang menjual berbagai macam produk salah satunya adalah handphone. Kualitas informasi dan kenyamanan berbelanja merupakan hal yang penting untuk diteliti karena akan mempengaruhi perilaku konsumen terhadap keputusan pembelian khususnya pada industri social commerce. Penelitian yang dilakukan oleh Park \& Kim, (2003) menemukan Kenyamanan berbelanja juga dianggap sebagai salah satu faktor yang dapat mempengaruhi keputusan pembelian secara online (R. et al. 2011).

Tujuan dari penelitian ini adalah untuk mengetahui gambaran kualitas informasi dan shopping enjoyment dan keputusan pembelian produk gadget pada Followers Instagram Kamar Gadget.

\section{KAJIAN PUSTAKA}

Pemasaran adalah proses komunikasi terpadu yang memberikan informasi tentang produk atau layanan yang berkaitan dengan pemenuhan kebutuhan masyarakat menurut Kotler \& Keller dalam (Ekaputri et al. 2016). Kotler \& Amstrong mengatakan pemasaran adalah proses dimana perusahaan menciptakan nilai bagi pelanggan dan membangun hubungan pelanggan yang kuat untuk mendapatkan nilai dari pelanggan sebagai imbalannya (Dirgantari 2013). Pemasaran digital secara umum sama dengan pemasaran tradisional, yaitu bagaimana pemasar berhubungan dengan konsumen untuk membangun hubungan dan akhirnya mendorong penjualan (Ryan 2014). Periset pemasaran telah mengembangkan model tingkat proses keputusan pembelian konsumen melalui tiga tahap yang berbeda namun berhubungan satu sama lain yaitu tahap input (external influence) yang menggambarkan pengaruh eksternal yang memberikan sumber informasi tentang produk tertentu dan mempengaruhi nilai, sikap dan perilaku.

Faktor eksternal tersebut terdiri dari: 1) usaha pemasaran perusahaan (yaitu: produk, promosi, harga, distribusi), dan 2) lingkungan sosial budaya (yaitu: keluarga, sumber informal, sumber nun komersial yang lain, kelas sosial, sub budaya dan budaya). Pada bagian proses berkaitan dengan bagaimana konsumen membuat keputusan. Pada bagian proses digambarkan pengaruh internal/psikologi (yaitu: motivasi, persepsi, belajar, kepribadian dan sikap) terhadap proses pengambilan keputusan. Pada bagian output berkaitan dengan aktivitas setelah keputusan, yaitu perilaku pembelian dan perilaku setelah pembelian.(Meiria 2017)

Perilaku konsumen dalam transaksi online berbeda dengan perilaku konsumen dalam transaksi biasanya. Perilaku mereka dipengaruhi oleh faktor pembelian pada umumnya dan juga pengaruh interaksi mereka dengan internet (Lisnawati Lisnawati, Razati Girang 2016). Pemahaman tentang kebutuhan dan keinginan konsumen yang disebabkan oleh sifat lingkungan online adalah hal yang penting karena hal tersebut kemudian dapat digunakan untuk meningkatkan pengalaman belanja dan memberikan personalisasi langsung yang didasarkan pada pengetahuan konsumen.(Molinari et al. 2008)

Konsumen dalam transaksi online hanya disajikan informasi-informasi mengenai produk yang dijual melalui media elektronik yang digunakan sebagai perantara bertransaksi secara online. Informasi yang disajikan sangat penting dalam bertransaksi online. Kualitas informasi yang baik dapat diukur dengan beberapa dimensi yaitu akurat, terkini, dan relevan (Kim et al. 2008) dalam transaksi secara online semua indikator tersebut sangat diperlukan oleh konsumen untuk membuat keputusan apakah akan membeli atau tidak terhadap suatu produk.

Selain kualitas informasi, (Kotler dan Armstrong, 2014) menyebutkan faktor internal yang dapat mempengaruhi perilaku konsumen antara lain persepsi yaitu motivasi, persepsi, gaya hidup, dan keyakinan atau kepercayaan dan sikap. Kajian online kenyamanan berbelanja berawal dari faktor motivasi yang kemudian berkembang kembali menjadi motivasi utilitarian dan hedonis .Ketersediaan 
informasi yang berkualitas memainkan peran penting dalam keberhasilan perusahaan (Hartono et al. 2010). Kualitas informasi lebih mengarah pada informasi yang akurat, terpercaya, tepat waktu, relevansi, mudah dipahami, sesuai dengan kebutuhan dan sesuai dengan format (Barnes \& Vidgen, 2002:122).

Konsep kualitas informasi telah mendapat banyak perhatian dari perilaku konsumen dan penelitian online shopping .mengatakan dalam beberapa tahun terakhir karena pengaruh kualitas informasi, komunitas online dan kepercayaan konsumen online sebagai faktor loyalitas konsumen online.

Dimensi kualitas informasi menurut (Hardiawan 2013) yaitu: 1) Informasi akurat, 2) Informasi up to date, 3) Informasi tepat waktu, 4) Informasi Relevan, 5) Informasi lengkap, 6) Format informasi yang disajikan menarik, 7) Informasi sesuai dengan tema, 8) Informasi mudah dimengerti, 9) Informasi berupa panduan. Sedangkan dimensi kualitas informasi menurut (Kaur Sahi \& Gupta 2013) yaitu: 1) Akurat, 2) Terkini. (Raman. 2012) menyebutkan tiga dimensi dalam kualitas informasi suatu produk yaitu: 1) Informasi produk, 2) Reputasi Website dan 3) Harga Produk.

Mengacu pada sejauh mana pengalaman berbelanja dengan toko online yang dianggap menyenangkan untuk diri konsumen. Kenyamanan berbelanja menyatakan seseorang yang suka dengan aktifitas belanja pada umumnya, memungkinkan untuk melakukan in-store browsing lebih lama dan merasakan kenikmatan pada saat berbelanja, meskipun konsumen tersebut tidak memiliki rencana untuk membeli dan hanya senang untuk browsing saja. Kenyamanan berbelanja didefinisikan sebagai kesenangan yang dihasilkan dari suatu proses belanja ((Kim et al. 2008).

Terdapat hal yang dapat membedakan antara belanja sebagai kegiatan yang dilakukan untuk utilitarian (fungsional atau nyata) atau hedonis (menyenangkan atau tidak berwujud). Salah satu item yang mengukur nilai hedonis adalah selama pengalaman belanja konsumen merasa gembira saat melakukan pencarian produk (M. R Solomon 2013). Terdapat enam kategori dari motivasi belanja hedonis yaitu 1) adventure shopping, 2) social shopping, 3) gratification shopping, 4) idea shopping, 5) role shopping, dan 6) value shopping. Role shopping merupakan kenyamanan yang pembeli rasakan bahwa kegiatan belanja membuat suasana hati pembeli menjadi gembira dan ketika pembeli menemukan produk sesuai dengan yang diinginkan.

Kenyamanan berbelanja yang merupakan salah satu faktor internal yang mampu mempengaruhi keputusan pembelian konsumen (Kotler dan Armstrong 2014). Kenyamanan menjadi prediktor yang konsisten dan kuat dari sikap terhadap belanja online (Nasrabadi \& Zandi 2015) Konsumen memiliki sikap positif terhadap belanja online dan mungkin bisa mengadopsi internet sebagai belanja kelas menengah.

Dimensi Kenyamanan Berbelanja menurut (Lim, W. M., \& Ting 2012) 1)Consumer empowerment orientation and interactivity, 2)User-generated Content 3)Attractiveness

\section{METODE PENELITIAN}

Penelitian ini menggunakan pendekatan manajemen pemasaran khususnya mengenai perilaku konsumen yaitu kualitas informasi dan shopping enjoyment. Adapun yang menjadi objek penelitian Kualitas Informasiunsurnya terdiri dari Akurat, terkini dan relevan, sedangkan kualitas informasi dan shopping enjoyment yang meliputi: consumer empowerment orientation and interactivity, user generated content dan attractiviness. Objek yang dijadikan responden dalam penelitian ini adalah pada Followers Instagram Kamar Gadget. Metode penelitian yang digunakan adalah metode explanatory survey. Explanatory survey dilakukan untuk mengeksplorasi situasi masalah, yaitu untuk mendapatkan ide-ide dan wawasan kedalam masalah yang dihadapi manajemen atau para peneliti tersebut (Maholtra 2010). Penelitian eksplanatori bertujuan untuk menjelaskan hubungan antara dua atau lebih gejala atau variabel (U Silalahi, 2012). Kesimpulan dari hasil penelitian survey ini berlaku umum (general) untuk seluruh wilayah yang menjadi sasaran. Berdasarkan pengertian explanatory survey menurut ahli, metode penelitian ini dilakukan melalui kegiatan pengumpulan informasi dari sebagian populasi secara langsung di tempat kejadian (empirik) dengan tujuan untuk mengetahui pendapat dari sebagian populasi terhadap objek yang sedang diteliti.

Penelitian ini dilakukan pada kurun waktu kurang dari satu tahun yaitu pada bulan September 2017. Pengumpulan informasi dari subjek penelitian hanya dilakukan satu kali dalam satu periode waktu, sehingga penelitian ini merupakan one-shot atau cross sectional (Maholtra 2010).

Metode yang dipergunakan dalam penelitian ini yaitu metode deskriptif. Penelitian ini bertujuan untuk memperoleh gambaran mengenai tanggapan 
konsep kualitas informasi dan shopping enjoyment pada Followers Instagram Kamar Gadget. Berdasarkan variabel-variabel yang diteliti, maka penulis menggunakan jenis penelitian deskriptif melalui pengumpulan data di lapangan, maka metode yang digunakan dalam penelitian ini adalah penelitian survey.

Operasionalisasi variabel merupakan kegiatan implementasi dari variabel ke dalam konsep teori dari variabel yang diteliti, indikator, ukuran dan skala yang bertujuan untuk mendefinisikan dan mengukur variabel. Variabel-variabel yang akan diteliti adalah variabel

Sumber data dalam penelitian adalah subyek dari mana data dapat diperoleh. Berdasarkan sumbernya, data dibedakan menjadi dua yaitu data primer dan data sekunder. Data primer adalah sumber yang langsung memberikan data kepada pengumpul data, dan data sekunder merupakan sumber yang tidak langsung memberikan data kepada pengumpul data (Sugiyono 2017). Dalam penelitian ini sumber data yang dipakai adalah: 1) Data Primer .Pada penelitian ini yang menjadi sumber data primer adalah instrumen yang disebarkan kepada sejumlah responden, sesuai dengan target sasaran dan dianggap mewakili seluruh populasi data penelitian, yakni survei pada Followers Instagram Kamar Gadget..2) Data Sekunder. Pada penelitian ini yang menjadi sumber data sekunder adalah literatur, jurnal, artikel serta situs internet yang berkenaan dengan penelitian.

Populasi dalam penelitian ini adalah pada Followers Instagram Kamar Gadget.yang diikuti 846 pengikut akun instagram Kamar Gadget. Agar memperoleh sampel yang representatif dari populasi maka setiap subjek dalam populasi diupayakan untuk memiliki peluang yang sama untuk menjadi sampel. Adapun rumus yang digunakan untuk mengambil suatu sampel dari sebuah populasi ialah dengan menggunakan rumus Slovin. Dalam penelitian ini ukuran sampel minimal adalah 240 responden. Pengumpulan data yang dilakukan penulis menggunakan teknik sebagai berikut:

Studi kepustakaan, yaitu suatu pengumpulan data dengan cara mempelajari buku, makalah, website dan majalah untuk memperoleh informasi yang berhubungan dengan teori dan konsep yang berkaitan dengan masalah dan variabel yang diteliti yang terdiri dari kualitas informasi, kenyamanan berbelanja, dan keputusan pembelian.

Studi lapangan yang terdiri dari penyebaran seperangkat pertanyaan secara online menggunakan Google Form dalam kuesioner. Penyebaran kuesioner dilakukan kepada followers instagram Kamar Gadget. Dalam kuesioner ini peneliti mengemukakan beberapa pertanyaan yang mencerminkan pengukuran indikator pada variabel kualitas informasi, kenyamanan berbelanja, dan keputusan pembelian . Kemudian memilih alternatif jawaban yang telah disediakan pada masing-masing alternatif jawaban yang tepat. Kuesioner yang disebar oleh peneliti di sebar secara umum kepada responden. Langkah-langkah penyusunan kuesioner adalah sebagai berikut:

Menyusun daftar pertanyaan secara online menggunakan Google Docs, dengan mengunjungi website www.drive.google.com, lalu login menggunakan akun Google. Pilih Create, lalu Form untuk memulai membuat kuesioner.

Kemudian setelah penyusunan kuesioner selesai, dilakukan penyebaran kuesioner tersebut pada sosial media seperti BBM, Line, Facebook, Twitter, Path, Whatsapp dan lainnya.

Setelah responden mengisi kuesioner, data akan secara otomatis masuk kedalam akun Google Form penulis. Terakhir data yang terkumpulkan kemudian dilakukan pemilihan sampel secara purposive berdasarkan data hasil kuesioner yang didapat.

Studi literatur merupakan usaha pengumpulan informasi yang berhubungan dengan teori yang ada kaitannya dengan masalah dan variabel yang diteliti yang terdiri dari kualitas informasi, kenyamanan berbelanja, dan keputusan pembelian. Studi literatur tersebut didapat dari berbagai sumber, yaitu: a) Perpustakaan Universitas Pendidikan Indonesia, b) Skripsi, c) Jurnal penelitian pemasaran, dan d) Media elektronik (Internet).

Wawancara yaitu dengan melakukan pertanyaan secara lisan dalam pertemuan tatap muka langsung terhadap individu atau kelompok yang sedang diteliti, dalam hal ini wawancara dibedakan menjadi dua macam yaitu:

Wawancara terstruktur, yang dugunakan apabila telah mengetahui dengan pasti tentang informasi apa yang diperoleh.

Wawancara tidak terstruktur adalah wawancara bebas dimana peneliti tidak menggunakan pedoman wawancara yang telah tersusun secara sistematis danlengkap dengan pengumpulan datanya.

Penelitian ini menggunakan teknik analisis data deskriptif. Teknik analisis deskriptif yaitu untuk variabel yang bersifat kualitatif. Penelitian ini menggunakan kuesioner sebagai alat untuk mengukur penelitian. Kegiatan analisis data dalam penelitian 
dilakukan melalui tahapan-tahapan sebagai berikut: 1) Menyusun data 2)Menyeleksi data untuk memeriksa kesempurnaan dan kebenaran data terkumpul 3)Tabulasi data 4)Pengujian

Penelitian ini menggunakan analisis deskriptif dengan distribusi frequensi untuk mendeskripsikan variabel kualitas informasi, shopping enjoyment dan keputusan pembelian

\section{HASIL PENELITIAN DAN PEMBAHASAN}

Kualitas informasi merupakan faktor penting untuk sebuah situs web yang dapat mempengaruhi keputusan pembelian konsumen (Utama et al. 2016) . (Ryan 2014) menunjukan bahwa terdapat pengaruh yang signifikan antara variabel kegunaan, kualitas informasi, dan kualitas interaksi layanan terhadap variabel keputusan pembelian online secara simultan. Sedangkan (Kotler \& Keller 2016) menyebutkan selain kualitas informasi, faktor internal yang dapat mempengaruhi perilaku konsumen antara lain persepsi yaitu motivasi, persepsi, gaya hidup, dan keyakinan atau kepercayaan dan sikap .Terdapat faktor lain yang dapat mempengaruhi keputusan pembelian secara online yaitu kenyamanan berbelanja yang merupakan salah satu faktor internal yang mampu mempengaruhi keputusan pembelian konsumen (Kotler dan Armstrong, 2014)).

Berikut rekapitulasi perolehan skor berdasarkan hasil pengolahan data variabel kualitas informasi: Tabel 1

Rekapitulasi Tanggapan Followers Instagram Kamar Gadget Terhadap Kualitas Informasi

\begin{tabular}{ccccc}
\hline No & Dimensi & Skor Total & $\begin{array}{c}\text { Skor } \\
\text { Rata-rata }\end{array}$ & Persentase\% \\
\hline 1 & Accurancy & 4336 & 1445 & $86,03 \%$ \\
2 & Up to Date & 5570 & 1393 & $82,89 \%$ \\
3 & Relevancy & 5608 & 1407 & $83,42 \%$ \\
\hline \multicolumn{2}{c}{ Total Skor } & $\mathbf{1 5 5 1 4}$ & $\mathbf{2 8 4 7}$ & $\mathbf{8 3 , 9 5 \%}$ \\
\hline
\end{tabular}

Sumber: Hasil Pengolahan Data 2017

Berdasarkan Tabel 1 hasil pengolahan data yang telah dilakukan melalui penyebaran instrumen kepada 240 responden Followers Instagram Kamar Gadget, apabila di persentasekan skor tertinggi terdapat pada dimensi Accurancy dengan persentase sebesar $86,03 \%$ dengan skor total sebesar 4336 . Sedangkan tanggapan yang terendah adalah pada dimensi $U p$ to Date dengan presentase yang sama yaitu sebesar $82,89 \%$ dengan perolehan skor total yaitu 5570 .

Hasil penelitian menyatakan bahwa kualitas informasi produk gadget pada Followers Instagram Kamar Gadget termasuk kedalam kategori tinggi. Dimensi yang memiliki skor paling tinggi terdapat pada dimensi Accurancy sedangkan dimensi yang memiliki skor paling rendah terdapat pada dimensi Up to Date. Sehingga dapat disimpulkan bahwa kualitas informasi produk gadget pada Followers Instagram Kamar Gadget sudah baik.

Kim et al., (2008) mengusulkan tiga dimensi dari kualitas informasi pada indikator yaitu: 1)Akurat, 2)Terkini, dan 3)Relevan, hal ini dikarenakan untuk menciptakan sebuah informasi yang berkualitas maka informasi tersebut harus akurat dan dapat diandalkan, serta tidak menyesatkan. Perolehan skor berdasarkan hasil pengolahan data variabel Kualitas Informasiadalah 15514 atau 83,95\%. Informasi yang disajikan diharapkan berguna dan relevan dalam memprediksi kualitas dan kegunaan suatu produk atau jasa. Informasi yang disajikan haruslah up to date dan akurat sehingga dapat memuaskan kebutuhan konsumen. Romney dan Steinbart yang diterjemahkan oleh (Utama et al. 2016) merangkum karakteristik informasi yang berkualitas ke dalam beberapa indikator yaitu:1)Relevan, informasi itu relevan jika mengurangi ketidakpastian, memperbaiki kemampuan pengambil keputusan untuk membuat prediksi, mengonfirmasikan, atau memperbaiki ekspektasi mereka sebelumnya; 2)Andal, informasi itu andal jika bebas dari kesalahan atau penyimpangan, dan secara akurat mewakili kejadian atau aktivitas di organisasi; 3)Lengkap, informasi itu lengkap jika tidak meninggalkan aspek-aspek penting dari kejadian yang merupakan dasar masalah atau aktivitas-aktivitas yang diukurnya; 4)Dapat dipahami, informasi dapat dipahami jika disajikan dalam bentuk yang dapat dipakai dan jelas; 5)Dapat diverifikasi, informasi dapat diverifikasi jika dua orang dengan pengetahuan yang baik, bekerja secara independen dan masing-masing akan menghasilkan informasi yang sama .

Kualitas informasi yang baik pada sebuah produk juga dapat terlihat berdasarkan intensitas sebuah informasi diperbarui dan diperiksa kebenarannya (Series \& Science 2017). Keakuratan dan intensitas pembaharuan informasi yang diberikan akan membuat konsumen merasa informasi tersebut relevan untuk membantu konsumen membuat keputusan dalam membeli (Hurriyati Ratih 2015). Konsep ini dikaitkan dengan konsep produk informasi yang menggunakan data sebagai masukan dan informasi didefinisikan sebagai data yang telah diolah sehingga memberikan makna bagi penerima informasi (Hurriyati 2016). Informasi yang berkualitas dapat meningkatkan pengambilan keputusan, meningkatkan pengelolaan sumber daya, membuat kebutuhan pelanggan menjadi lebih mudah, dan memberikan nilai lebih terhadap perusahaan (Buyukozkan, Arsenyan, \& Ruan, 2012; Davis \& Golicic, 2010; Gorla, Somers, \& Wong, 2010; See, 2007) 
Berikut rekapitulasi perolehan skor berdasarkan hasil pengolahan data variabel shopping enjoyment:

$$
\text { TABEL } 2
$$

REKAPITULASI TANGGAPAN RESPONDEN FOLLOWERS INSTAGRAM KAMAR GADGET TERHADAP KENYAMANAN BERBELANJA

\begin{tabular}{clccc}
\hline No & \multicolumn{1}{c}{ Dimensi } & Skor Total & $\begin{array}{c}\text { Skor } \\
\text { Rata-rata }\end{array}$ & Persentase\% \\
\hline 1 & $\begin{array}{l}\text { Consumer empowerment } \\
\text { orientation and interactivity }\end{array}$ & 5599 & 1400 & $83,28 \%$ \\
2 & User-generated Content & 2815 & 1408 & $83,78 \%$ \\
3 & Attractiveness & 2860 & 1430 & $85,12 \%$ \\
\hline \multicolumn{2}{c}{ Total Skor } & $\mathbf{1 1 2 7 4}$ & $\mathbf{1 4 1 2}$ & $\mathbf{8 3 , 8 8 \%}$ \\
\hline
\end{tabular}

Sumber: Hasil Pengolahan Data 2017

Berdasarkan Tabel 2 hasil pengolahan data yang telah dilakukan melalui penyebaran instrumen kepada 240 responden Followers Instagram Kamar Gadget, apabila di persentasekan skor tertinggi terdapat pada dimensi Attractiveness dengan persentase sebesar $85,12 \%$ dengan skor total sebesar 2860. Sedangkan tanggapan yang terendah adalah pada dimensi Consumer empowerment orientation and interactivity dengan presentase yaitu sebesar 83,28\% dengan perolehan skor total 5599. Motivasi pembelian dan konsumsi diklasifikasikan dalam dua jenis, yaitu motif belanja sebagai kegiatan yang dilakukan untuk utilitarian (fungsional atau nyata) dan hedonis (menyenangkan atau tidak berwujud). Motif belanja hedonis didasarkan pada emosi, perasaan nyaman dan gembira, sedangkan motif belanja utilitarian didasarkan pada motif kemanfaatan fungsi belanja.

Terdapat enam kategori besar dari motivasi belanja hedonis, yaitu: 1) adventure shopping (petualangan belanja) mengacu pada belanja untuk stimulasi, petualangan dan perasaan berada di dunia lain, 2) social shopping (belanja sosial) mengacu pada kenikmatan berbelanja dengan teman-teman dan keluarga, bersosialisasi saat berbelanja dan ikatan dengan orang lain saat berbelanja, 3) gratification shopping (gratifikasi belanja) melibatkan belanja untuk menghilangkan stres, belanja untuk meringankan suasana hati negatif dan belanja sebagai hadiah khusus untuk diri sendiri, 4) idea shopping (ide belanja) mengacu pada belanja untuk mengikuti tren dan mode baru dan untuk melihat produk baru dan inovasi, 5) role shopping (peran belanja) mencerminkan kenyamanan (enjoyment) yang pembeli rasakan bahwa kegiatan belanja membuat suasana hati pembeli menjadi gembira dan saat pembeli menemukan produk yang diinginkan, dan 6) value shopping (nilai belanja) mengacu pada belanja untuk penjualan, mencari diskon dan berburu barang murah (Michael R Solomon 2013).

(Lim, W. M., \& Ting 2012) mengusulkan terdapat tiga dimensi yang mempengaruhi kenyamanan berbelanja, yaitu: 1) consumer empowerment orientation dan interactivity, 2) user generated content dan 3) attractiveness. Perolehan skor berdasarkan hasil pengolahan data variabel shopping enjoyment adalah 11274 atau 83,88\%. Kenyamanan berbelanja akan berdampak pada pengalaman berikutnya, jika konsumen merasa senang dan membangkitkan rangsangan selama pengalaman belanja online, maka konsumen lebih cenderung terlibat dalam perilaku pembelian berikutnya. Kenikmatan belanja mencerminkan persepsi konsumen mengenai hiburan dalam berbelanja online (Hurriyati 2016). Para konsumen akan menyukai bahwa berbelanja online itu mudah dan menyenangkan. Hubungan antara kenikmatan belanja dengan minat membeli secara online dan menunjukkan hasil sesuai dalam kaitannya dengan motivasi . Motivasi adalah kenikmatan belanja, maka kenikmatan belanja termasuk sebagai variabel yang berpengaruh terhadap minat konsumen. Kenyamanan belanja diciptakan dari kesenangan selama pengalaman belanja online, bukan dari penyelesaian aktivitas berbelanja(Wibowo 2006; Series \& Science 2017; Hurriyati 2016; Devindiani 2016).

Hasil penelitian menyatakan bahwa shopping enjoyment produk gadget pada Followers Instagram Kamar Gadget termasuk kedalam kategori tinggi. Dimensi yang memiliki skor paling tinggi terdapat pada dimensi attractiveness sedangkan dimensi yang memiliki skor paling rendah terdapat pada dimensi consumer empowerment orientation and interactivity. Sehingga dapat disimpulkan bahwa kualitas informasi produk gadget pada Followers Instagram Kamar Gadget sudah baik.

Berikut rekapitulasi perolehan skor berdasarkan hasil pengolahan data variabel keputusan pembelian:

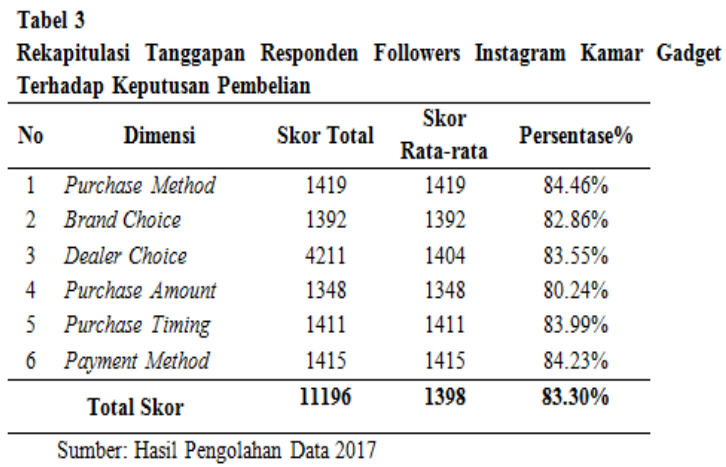

Berdasarkan Tabel 3 hasil pengolahan data yang telah dilakukan melalui penyebaran instrumen 
kepada 240 responden Followers Instagram Kamar Gadget, bahwa dimensi yang memperoleh skor tertinggi adalah dimensi Purchase Method dengan persentase sebesar $84.46 \%$ dengan skor total sebesar 1419. Sedangkan tanggapan yang terendah adalah pada dimensi Purchase Amount dengan presentase yang sama yaitu sebesar $80.24 \%$ dengan perolehan skor total 11196.

(Tarmedi \& Asri n.d.) berpendapat bahwa kegiatan e-commerce dan belanja online akan mengandalkan kecakapan pembeli berinteraksi dengan komputer. Dengan kata lain keputusan pembelian online merupakan kecakapan atau kemampuan seorang pembeli mampu berinteraksi dengan komputer atau memanfaatkan media tersebut untuk membantunya dalam membuat keputusan, sehingga ketika konsumen memilih melakukan keputusan pembelian secara online, konsumen harus mampu berinteraksi dengan komputer agar informasi mengenai produk yang akan dibeli didapatkan sesuai keinginan (Paribhasagita, 2016).

Hasil penelitian menyatakan bahwa keputusan pembelian produk gadget pada Followers Instagram Kamar Gadget termasuk kedalam kategori tinggi. Dimensi yang memiliki skor paling tinggi terdapat pada dimensi Accurancy sedangkan dimensi yang memiliki skor paling rendah terdapat pada dimensi Up to Date. Sehingga dapat disimpulkan bahwa keputusan pembelian produk gadget pada Followers Instagram Kamar Gadget sudah baik. Menurut Turban, Efraim, David \& Judy (2011) faktor-faktor yang mempengaruhi proses pengambilan keputusan konsumen adalah: 1)Karakteristik pribadi yang terdiri dari usia, gender, etnis, pendidikan, gaya hidup, psikologis, pengetahuan, nilai dan kepribadian.2)Karakteristik lingkungan yang terdiri dari sosial, keluarga, komunitas, masyarakat.3)Karakteristik penjual yaitu reputasi merk, stimulus pemasaran seperti pengetahuan tentang produk, kualitas produk, harga, ketersediaan produk, tipe produk.

Dimensi keputusan pembelian menurut (Kotler, P., \& Armstrong 2013) adalah sebagai berikut: 1) purchase method, 2) brand choice, 3) dealer choice, 4) Site awareness, 5) purchase amount, 6) purchase timing, (7) payment method. Periset pemasaran telah mengembangkan model tingkat proses keputusan pembelian konsumen melalui tiga tahap yang berbeda namun berhubungan satu sama lain yaitu tahap masukan (input), tahap proses dan tahap keluaran (output). Istilah ini digunakan ketika konsumen memiliki kemampuan untuk mencari, memilih dan melakukan pembelian produk melalui internet(Erisha 2016). pembelian online adalah bagaimana konsumen membuat keputusan tentang produk atau jasa apa yang akan dibeli secara online. Keputusan pembelian dapat dipengaruhi oleh faktor-faktor dimensi yaitu Purchase method,Brand choice, Dealer choice, Purchase amount, Purchase timing, dan Payment method oleh Kotler \& Armstrong (2014:176-178).

\section{KESIMPULAN}

Berdasarkan uraian teori yang dikemukakan oleh para ahli serta hasil penelitian penerapan kualitas informasi dan shopping enjoyment produk gadget pada Followers Instagram Kamar Gadget didapat kesimpulan:

Hasil penelitian menyatakan bahwa kualitas informasi produk gadget pada Followers Instagram Kamar Gadget termasuk kedalam kategori tinggi. Dimensi yang memiliki skor paling tinggi terdapat pada dimensi Accurancy sedangkan dimensi yang memiliki skor paling rendah terdapat pada dimensi Up to Date. Sehingga dapat disimpulkan bahwa kualitas informasi produk gadget pada Followers Instagram Kamar Gadget sudah baik.

Hasil penelitian menyatakan bahwa shopping enjoyment produk gadget pada Followers Instagram Kamar Gadget termasuk kedalam kategori tinggi. Dimensi yang memiliki skor paling tinggi terdapat pada dimensi attractiveness sedangkan dimensi yang memiliki skor paling rendah terdapat pada dimensi consumer empowerment orientation and interactivity. Sehingga dapat disimpulkan bahwa kualitas informasi produk gadget pada Followers Instagram Kamar Gadget sudah baik.

Hasil penelitian menyatakan bahwa keputusan pembelian produk gadget pada Followers Instagram Kamar Gadget termasuk kedalam kategori tinggi. Dimensi yang memiliki skor paling tinggi terdapat pada dimensi Accurancy sedangkan dimensi yang memiliki skor paling rendah terdapat pada dimensi Up to Date. Sehingga dapat disimpulkan bahwa keputusan pembelian produk gadget pada Followers Instagram Kamar Gadget sudah baik.

\section{DAFTAR PUSTAKA}

Akhlaq, A., \& Ahmed, E., 2015. Digital commerce in emerging economies. International Journal of Emerging Markets.

Barnes, S.J. \& Vidgen, R.T., 2002. An Integrative Approach To The Assessment Of E-commerce 
Quality. Journal of Electronic Commerce Research, 3(3), pp.114-127.

Bu“yu"ko“zkan, G., Arsenyan, J. \& Ruan, D., 2012. Logistics tool selection with two-phase fuzzy multi criteria decision making: a case study for personal digital assistant selection. Expert Systems with Applications, 39, pp.142-153.

Davis, D.F. \& Golicic, S.L., 2010. Gaining comparative advantage in supply chain relationships: the mediating role of marketoriented IT competence. Journal of the Academy of Marketing Science, 38, pp.56-70.

Devindiani, $\quad$ E., $2016 . \quad$ PENGARUH EXPERIENTIAL MARKETING TERHADAP CUSTOMER SATISFACTION SERTA DAMPAKNYA PADA CUSTOMER LOYALTY ( Survei pada Pengguna Smartphone di Komunitas Online Apple dan Samsung Regional Bandung ). , 1(1), pp.147157.

Dirgantari, P.D., 2013. Peranan Bauran Pemasaran Jasa Pendidikan Terhadap Upaya Meningkatkan Ekuitas Merek Berbasis Pelanggan Perguruan Tinggi (Studi Pada Perguruan Tinggi Di Jawa Barat). Pendidikan Manajemen Bisnis, 216, pp.22-31.

Ekaputri, A.H., Rahayu, A. \& Wibowo, L.A., 2016. The Effect of Brand Experience on Customer Satisfaction and The Impact toward Repurchase Intention. , 15, pp.464-467.

Erisha, M., 2016. PENGARUH KINERJA PEOPLE DAN PHYSICAL EVIDENCE TERHADAP KEPUTUSAN MENGINAP ( Survei Terhadap Tamu Hotel Kampung Sumber Alam Garut ). , 1(2), pp.17-24.

Gorla, N., Somers, T.M. \& Wong, B., 2010. Organizational impact of system quality, information quality, and service quality. The Journal of Strategic Information Systems, 19(2), pp.7-28.

Hardiawan, C.A., 2013. Pengaruh Kepercayaan, Kemudahan, dan Kualitas Informasi Terhadap Keputusan Pembelian Secara Online (Studi Pada Pengguna Situs Jual Beli Online tokobagus.com).

Hartono, E. et al., 2010. The role of the quality of shared information in interorganizational systems use. International Journal of Information Management, 30, pp.399-407.

Hurriyati, R., 2016. Learning Model of Entreupreuneurship Using Business Incubator Based on Web 2 . 0 Technology. , (Icieve 2015), pp.22-25.

Hurriyati Ratih, L., 2015. The Effect Of National Identity, Cosmopolitanism And Ethnocentrism On Purchase Behavior Of Domestics And
Foreign Products. Social Science, Education and Humanities Research.

Kaur Sahi, G. \& Gupta, S., 2013. Predicting customers' behavioral intentions toward ATM services. Journal of Indian Business Research, 5(4), pp.251-270.

Kim, D.J., Ferrin, D.L. \& Rao, H.R., 2008. A TrustBased Consumer Decision Model in Electronic Commerce: The Role of Trust, Risk, and Their Antecedents. Decision Support Systems, 44(2).

Kotler, P., \& Armstrong, G., 2013. Principles of Marketing (15th Editi), PEARSON.

Kotler, P. \& Armstrong, G., 2010. Principles of Marketing. World Wide Web Internet And Web Information Systems, p.785. Available at: http://www.amazon.com/dp/0139570020.

Kotler, P. \& Keller, K.L., 2016. Marketing Management 15th Editi., USA: PEARSON.

Kotler dan Armstrong, 2014. No Title. Principles of Marketing.

Kusumadewi, A., \& Bobby, A., 2012. Era Pemasaran Online, Pengusaha Harus Jeli.

Lim, W. M., \& Ting, D.H., 2012. E -shopping: an Analysis of the Technology Acceptance Model.

Lisnawati Lisnawati, Razati Girang, M.H., 2016. Service Quality and Reputation Toward Customer Trust in Life Insurance Corporation. , 15(2016).

Maholtra, K.N., 2010. Marketing Reseach: An Applied Orientation Sixth Ed Pearson Education Sixth edit., Pearson Education.

Meiria, E., 2017. Ekuitas Merek dan Keputusan Pembelian: Studi Pada Konsumen Anak Usia Sekolah Dasar di Kota Depok. Esensi, 7(1), pp.111-130. Available at: http://journal.uinjkt.ac.id/index.php/esensi/artic le/view/4783.

Molinari, L.K., Abratt, R. \& Dion, P., 2008. Satisfaction, quality and value and effects on repurchase and positive word-of-mouth behavioral intentions in a B2B services context. Journal of Services Marketing, 22/5.

Nasrabadi, E.M. \& Zandi, P., 2015. Investigating the Impact of Marketing Mix on Brand Equity (The Case Study: Consumers of Samsung's Appliances in Tehran-Iran). , 2015(2), pp.2026.

Paribhasagita, T., 2016. PENGARUH CUSTOMER RELATIONSHIP MANAGEMENT TERHADAP LOYALITAS NASABAH ( Survei pada Nasabah Asuransi Jiwa Prudentual Cabang Kota Bandung )., 1(1), pp.37-53.

Park, C.-H. \& Kim, Y.-G., 2003. Identifying key factors affecting consumer purchase behavior in an online shopping context. International Journal of Retail \& Distribution Management, 
31(1), pp.16-29.

R., A., Shahbazi, D. \& Teimouri, M.E., 2011. The Role of Security as a Customer Perception on Customers' Online Purchasing Behavior. International Conference on Software and Computer Applications, 9, p.2011.

Raman., \& A., 2012. Marketing the Lifeline of NetGeneration: An Empirical Study.

Raman, A. \& Annamalai, I., 2012. E-Marketing the Lifeline of NetGeneration: An Empirical Study. , 3(2), p.2012.

Resa, A.L. et al., 2009. PENUNJANG PERKEMBANGAN E-COMMERCE. , pp.1723.

Ryan, D., 2014. Understanding Digital Marketing: Marketing Strategies for Engaging the Digital Generation. Understanding Digital Marketing, p.2014.

See, W., 2007. Wireless technologies for logistic distribution process. Journal of Manufacturing Technology Management, 18, pp.876-88.

Series, I.O.P.C. \& Science, M., 2017. Improving the Competitiveness of UPI as a Research-Based
Teaching Improving the Competitiveness of UPI as a Research-Based Teaching University. Solomon, M.R., 2013. Consumer Behavior : Buying, Having, and Being 10th ed., New Jersey: Person Education Limited, England.

Solomon, M.R., 2013. Consumer Behavior : Buying, Having, and Being (10th ed.). Person Education Limited, England.

Sugiyono, 2017. Metode Peneitian Kuantitatif, Kualitatif, dan Kombinasi (Mixed Methods), Bandung: Alfabeta.

Tarmedi, E. \& Asri, P.N., PENGARUH PERCEIVED QUALITY DARI BRAND EQUITY TERHADAP. , pp.35-49.

U, S., 2012. Metode Penelitian Sosial, Bandung: Refika Aditama.

Utama, R.D.H., S, B.L.N. \& Sutarni, N., 2016. Entrepreneurship Intention to Trigger Entrepreneurship Orientation. , 15, pp.706-710.

Wibowo, L.A., 2006. PENGARUH METODE COOPERATIVE LEARNING TEKNIK JIGSAW. , pp.520-528. 